\title{
LAS REPRESENTACIONES
SOCIALES DE LA VEJEZ \\ UN MODELO DE AMPLIACIÓN \\ DE CIUDADANÍA
}

THE SOCIAL REPRESENTATIONS

OF OLD AGE. A MODEL OF

EXTENDED CITIZENSHIP

Cristina Ester Marzioni
Lucía Viviana Billoud

RESUMEN / La "representación social", su relación con la normativa, proyectos de investigación, las transformaciones jurídicas y sociales para la vejez; su condición de ciudadanos. Trabajar conceptos de representación social, pautas para ejercicio de derechos, información, imagen social, de autonomía, capacidad y participación. Pensar la vejez en la sociedad y dichas transformaciones: sexualidad, imagen social, lesión de derecho, derechos y deberes en procesos de familia, estigma de identidad en capacidad y autonomía, derecho al propio cuerpo, institutos que lo regulan, redes, ayuda social; relaciones de familia; principios generales materiales y procesales, la participación y demás principios de Naciones Unidas. Las formas de interpretación en base a los fines, tratados de DDHH, principios, valores, prácticas, costumbres: paradigma de la "constitucionalización" del derecho; igualdad real de oportunidades, exigibilidad/ejercicio de derechos y libertades para garantizar y no solo proclamarlos. Clausurar la fisura que separa los derechos de todos los hombres de las de algunos ciudadanos. Conformar nuevo paradigma facilitador de revalorización de la persona, su humanización, centralidad, de su protección integral efectiva; abrir el camino de las Ciencias hacia nuevos criterios para la vida de estos sujetos.

PALABRAS CLAVE / ciudadanía; personas mayores; representación social; nuevos derechos; principios y valores; ejercicio de derechos
ABSTRACT / "Social representation", its relationship with regulations, research projects, legal and social transformations for the elderly; your status as citizens. Work on concepts of social representation, guidelines for exercising rights, information, social image, autonomy, capacity and participation. Think of the elderly in society and these transformations: sexuality, social image, injury of law, rights and duties in family processes, stigma of identity in capacity and autonomy, right to the body itself, institutes that regulate it, networks, social assistance; family relationships; general material and procedural principles, participation and other principles of the United Nations. The forms of interpretation based on the ends, human rights treaties, principles, values, practices, customs: paradigm of the "constitutionalization" of law; real equality of opportunities, enforceability / exercise of rights and freedoms to guarantee and not only proclaim them. Close the fissure that separates the rights of all men from those of some citizens. Conform new facilitating paradigm of revaluation of the person, their humanization, centrality, of their effective integral protection; open the path of Science towards new criteria for the life of these subjects.

KEY WORDS / citizenship; the elderly; social representation; new rights; principles and values; exercise of rights 
La temática guarda vinculación con el PI № 50120110100364-2009/2017 «Un Modelo de Ampliación de Ciudadanía: El acceso a la justicia ${ }^{1}$ de los adultos mayores, grupo de y en riesgo, como garantía de igualdad» y el actual en ejecución, № 50120150100223LI, 2017/2020: «Un Nuevo Modelo de Ampliación de Ciudadanía a partir de las transformaciones jurídicas y sociales del Nuevo Código Civil y Comercial de la Nación Argentina para los Adultos Mayores desde la ciudad de Santa Fe».

La materia que refiere este artículo es la adecuación al nuevo paradigma jurídico-político-social de protección integral de derechos. Supone clausurar la fisura que separa los derechos de todos los hombres de los de algunos ciudadanos (Ferrajoli, Cittadanza: 263, 292). Cerrar la laguna jurídica es comenzar a pensar distinto hacia la plenitud de sus derechos.

Ambas investigaciones tratan un nuevo modelo de ampliación de ciudadanía para las personas mayores. En la primera se indaga sobre la representación social de las mismas en relación al sistema de justicia. Reconocer las representaciones sociales que construyen los medios de comunicación social; que posee la administración de justicia y las personas mayores en relación a la misma sobre sus conflictos interpersonales judicializados. Saber los grados de participación de ellas respecto al conocimiento, respeto y fortalecimiento de sus derechos, principios y libertades. En la segunda, establecer los alcances de la nueva regulación respecto de la población adulta mayor (PAM) y analizar los nuevos institutos protectorios del derecho positivo interno argentino: las transformaciones jurídicas y sociales del Código Civil vigente y del acceso a la justicia para las personas mayores y la protección de derechos, garantías y libertades desde el nuevo paradigma constitucional. En ambos casos supone otorgar protección de "tutela real efectiva» de los derechos y libertades de las personas mayores; así como tratar de lograr la igualdad real de oportunidades (art. 75 inc. 23 CN). Todo ello hace posible la exigibilidad/ejercicio de derechos y libertades a fin de garantizar y no simplemente proclamar los derechos de todos (Corte Interamericana De Derechos Humanos e Informe De DDHH 2005). «La ciudadanía es incompatible con el privilegio que por definición es una negación de la

1 Acceso a la justicia es un principio básico del estado de derecho: "un acceso de todos a los beneficios de la justicia y del asesoramiento legal y judicial, en forma adecuada a la importancia de cada tema o asunto, sin costos o con costos accesibles, por parte de todas las personas físicas o jurídicas, sin discriminación alguna por sexo, raza o religión (...)Es un derecho fundamental que debe garantizarse en una sociedad democrática, participativa e igualitaria, que tienen todos los individuos a utilizar las herramientas y mecanismos legales para que se reconozcan y protejan sus demás derechos". 
ciudadanía de los otros. Cuando se trastocan los derechos de todos en privilegio de algunos, no hay ciudadanos hay señores que a su arbitrio distribuyen premios y castigos entre sus seguidores» (Birgin y Cohen, 2006:18).

El tópico «representaciones sociales de la vejez» es relevante porque supone preguntarse qué papel juegan estas imágenes en las personas mayores cuando se tratan los institutos jurídicos en el CCC vigente, que devienen en transformaciones jurídicas y sociales inéditas para nuestro país. En especial, porque éste refiere al paradigma de la «constitucionalización» del derecho; donde están involucrados principios rectores materiales y procesales, prácticas y valores jurídicos y sociales. El codificador lo deja claramente explicitado en el Capítulo 1 «Derecho» del Título Preliminar que por su relevancia se transcribe:

Art $1^{\circ}$. Los casos que este Código rige deben ser resueltos según las leyes que resulten aplicables, conforme con la Constitución Nacional y los tratados de derechos humanos en los que la República sea parte. A tal efecto, se tendrá en cuenta la finalidad de la norma, los usos, prácticas y costumbres vinculantes cuando las leyes o los interesados se refieren a ellos o en situaciones no regladas legalmente, siempre que no sean contrarios a derecho. Art $2^{\circ}$. Interpretación. La ley debe ser interpretada, teniendo en cuenta sus palabras, sus finalidades, las leyes análogas, las disposiciones que surgen de los tratados sobre derechos humanos, los principios y los valores jurídicos, de modo coherente con todo el ordenamiento. Art. $3^{\circ}$. Deber de resolver. El juez debe resolver los asuntos que sean sometidos a su jurisdicción mediante una decisión razonablemente fundada. (Código Civil: 35)

Bajo este título se receptan las definiciones sobre las fuentes del derecho, sus reglas de interpretación y se regula como principio general la obligación de decidir razonablemente. Se establecen pautas generales para el ejercicio ciudadano de los derechos - en el caso de las personas mayorescon cláusulas generales sobre buena fe (art.9), abuso de derecho (art.10), fraude a la ley (art.12). Se reconocen además los derechos individuales de las personas sobre sus bienes y sobre su propio cuerpo.

En función de estas investigaciones se pretende realizar un vínculo entre la participación real de personas mayores - en torno a derechos, principios y libertades que les pertenecen, el conocimiento e información acerca de los mismos y los alcances de la nueva regulación respecto de la PAM-. Es decir el modelo de ampliación de ciudadanía para estas personas cruzado con las representaciones sociales y el envejecimiento. Las representaciones entran a escena cuando se pregunta en qué medida estas perso- 
nas conocen y ejercen sus derechos y libertades; la razón por la que tales principios jurídicos fueron modificados a la luz de transformaciones sociales en torno a qué significa ser un adulto mayor; cuáles son sus formas de actuar y sus expectativas. El estudio de las representaciones sociales sobre el envejecimiento dio lugar a que nuestra legislación, de espacio a la singularidad y especificidad de los derechos de las personas de edad.

\section{Las representaciones sociales}

Retomando los argumentos esgrimidos por Jodelet (1986:593):

El concepto de representación social designa una forma de conocimiento específico, el saber de sentido común, cuyos contenidos manifiestan la operación de procesos generativos y funcionales socialmente caracterizados. En sentido más amplio designa una forma de pensamiento social. Las representaciones sociales constituyen modalidades de pensamiento práctico orientados hacia la comunicación, la comprensión y el dominio del entorno social, material e ideal. En tanto que tales [sic], presentan características específicas a nivel de organización de los contenidos, operaciones mentales y lógica.

El estudio de las representaciones sociales es tenido en cuenta en nuestra investigación, en tanto permiten entender las imágenes preconcebidas que la sociedad comparte sobre las personas mayores y dan lugar a una configuración específica de su trayectoria, atravesada por expectativas individuales sobre la propia vida, los roles y actitudes socialmente esperadas para cada edad en un momento histórico-social-cultural específico. Éstas se constituyen como «modelos imaginarios de evaluación, clasificación y explicación de las realidades sociales, que conducen hacia normas individuales y colectivas para la acción»: (Gastrón, 2013: 25). Asimismo, la autora sostiene que son construcciones ya que no es una simple reproducción de formas de ver el mundo social, sino que se constituye en una constante construcción de imágenes a través de la experiencia que adquiere el sujeto en un mundo cultural y social específico.

Para comprender las representaciones sociales se las deben desglosar en tres partes: la información, el campo de representación y la actitud.

«La información ${ }^{2}$ es la suma de conocimientos que se posee sobre un grupo social (...) Es decir en nuestro caso la información estaría dada por el

2 Por otra parte si se mira desde la óptica jurídica el derecho la información es un derecho llamado 
conjunto de conocimientos que el personal, los propios adultos mayores y la sociedad en general asocian al envejecimiento a partir de una construcción del sentido común. El campo de representación es el conjunto estructurado de la representación» (Gastrón, 2013:27). Ello significa un grupo de imágenes asociadas a un determinado estereotipo de adulto mayor que tiene el personal de la institución por ejemplo. «La actitud expresa la orientación positiva o negativa de un grupo hacia el objeto de representación» (Gastrón, 2013:27) lo cual remite a las emociones y sentimientos que provoca la presencia de la persona mayor en diversos espacios.

El enfoque de las mismas supone indagar elementos subjetivos de las propias personas mayores con elementos contextuales, jurídicos y sociales, las vivencias de ellas en un momento específico de su vida y en un contexto particular.

Caracterizar la vejez y el envejecimiento en el campo representacional permite incorporar y articular fenómenos y situaciones vitales como partes de un engranaje hasta ahora invisibilizados. Aparecen las prescripciones y las represiones sociales acerca de la sexualidad, los afectos, el cuerpo, el paso del tiempo, el miedo a la muerte, la religiosidad; así como los permisos, las obligaciones, las contradicciones, las imágenes engañosas y las falsas percepciones. Se confunde apariencia con realidad, donde la apariencia es realidad. (Gastrón, 2013:176)

Analizar las representaciones sociales sobre el envejecer como proceso, permite otorgar nuevas significaciones a los conceptos tradicionales, enfocados desde una perspectiva integral e integradora; aparecen otras dimensiones de relevancia y que se deben tener en cuenta al momento de canalizar la temática, como es el de la resolución judicial decisión judicialmente razonada: los elementos cognitivos, el mundo afectivo, los aspectos normativos y actitudinales y el contexto cultural y social en el cual está inserta la persona.

de "cuarta generación" reconocido en Tratados de Derechos Humanos (Art. 75, inciso 22 Constitución Nacional), consagrado en el art. 43 de la carta magna (Nuevos derechos y garantías). Es donde se encuentra el fundamento del sistema democrático de gobierno. Forma parte de las garantías individuales y es condición de ciudadanía. En la naturaleza de éste subyacen los requisitos más elementales y previos de toda democracia: la transparencia del ejercicio público, el debate e intercambio de ideas e informaciones, la rendición de cuentas, la asunción de reglas claras en todos los terrenos de la vida social y política. 
El viejismo. La imagen social de la vejez

El concepto de viejismo (ageism, en inglés) fue elaborado por el gerontólogo Robert Butler en 1968 y "se refiere a la discriminación que se hace sobre ciertas personas meramente por el hecho de acumular años y basado en la utilización de prejuicios» (Salvarezza, 2013:21). Esa representación social sobre los adultos mayores está arraigada en la negación del envejecimiento de los propios sujetos que usan el concepto "viejo», «enfermo", «débil», relacionándolo con el grupo de sujetos que se encuentran bajo la etiqueta de vejez, para así negar su propio proceso de envejecimiento. Estos conceptos degradan la consideración sobre sí mismos, se autolimitan y conlleva a tener un auto-concepto degradante. Los estereotipos negativos sobre la vejez se ven tan internalizados en las personas mayores cuanto más estos sujetos tiendan a ser como se les dice que sean. Así «las personas, al suponer que su rendimiento no va a ser bueno, elaboran estrategias de evitación de un posible enfrentamiento que podría ser vivido como traumático o simplemente porque responden a profecías sociales que suponen que los mayores ya no pueden, ya no deben» (Iacub, 2014:82).

El discurso social construye un tipo homogéneo de vejez que conlleva a una identificación única de persona mayor como sujeto inútil, sin capacidad de actuar frente a un contexto social que en cierto momento de su vida, le indica que su existencia sólo se reduce a incapacidades de todo tipo. La imagen está asociada a la pérdida de independencia con el consiguiente deterioro físico y mental y asociada con la pérdida de relaciones sociales, de roles sociales, condición socioeconómica, factor ambiental, niveles de carencias, necesidades básicas insatisfechas, contaminación, ausencia del proyecto familiar y falta de integración comunitaria.

La imagen de la vejez es como mirarse en un espejo, el temor al deterioro. Dicha imagen está construida a través de y en un proceso social y familiar a partir del cual la persona mayor es considerada, al llegar a la vejez, portadora de un cuerpo deficiente, decadente y enfermo. De modo que con el avance de los años lo único que puede verse en estos sujetos es un conjunto de pérdidas mentales, cognitivas, afectivas y relacionales que vienen a conjugarse con un cuerpo con mayor dependencia funcional para el aseo personal, las tareas del hogar y otros tipos de actividades.

El desarrollo del envejecimiento de estas personas desde la óptica de la sociedad, instituye un proceso excluyente de roles de interacción, cotidianeidad y la propia identidad y un conjunto de pérdidas sobre su propia vida, rutina e intereses; teniendo en cuenta las representaciones y prácticas 
sociales e institucionales que confluyen en la consideración de la vejez como un período de la vida despojante de todo tipo de capacidades y atributos.

Como se explicita el conocimiento de la sociedad en torno a la vejez se basa en mitos, estereotipos y prejuicios que desestiman a la persona de edad. Las creencias son una forma existente para programar nuestra conciencia. Suelen ser silenciosas y es algo a lo que los sujetos se aferran porque consideran que es verdad. El aporte de las investigaciones en Ciencias Sociales y Jurídicas consiste en gestionar las herramientas para que los sujetos, las instituciones la sociedad se permitan cuestionar las ideas preconcebidas sobre el envejecimiento.

Otro aspecto fundamental en la vida de las personas de edad avanzada en todas partes del mundo lo constituyen las relaciones familiares. La familia asegura el bienestar afectivo y material y absorbe el impacto de las crisis sociales. Juegan aquí la soledad y el aislamiento (Marzioni, 2019). Creecry, Berg y Wright concluyeron que el sentimiento de soledad no se ve influenciado ni por la edad ni por el sexo, sino que resulta de la compleja interacción de diferentes variables sociales (actividad y satisfacción social) y socio-demográficas (estado civil, ingresos y salud auto percibida), siendo la satisfacción social la variable que mejor predica la «soledad (Llorente Crabero, 1991).Al aumentar la edad (cuanto más avanzada) tenemos más posibilidades de perder relaciones sociales (trabajo, seres queridos, etc.) así como un desgaste en nuestro estado de salud. Es importante entender que las relaciones sociales varían a lo largo de la vida del sujeto y que hemos de estar constantemente adaptándonos a ellos. La soledad en la vejez es uno de los mitos que no se ve confirmado por los estudios realizados al respecto, dado que la soledad es un sentimiento y como tal subjetivo, que va a depender -como ya se ha mencionado- de otros muchos factores que tienen poco que ver con la edad que se tenga.

La consideración del desarrollo humano desde el punto de vista de la situaciones de sobrecarga, problemáticas y conflictivas, hunde indudablemente sus raíces en la psicología profunda. Surge así otro aspecto en la personas de edad: el conflicto. El mismo es una forma básica de la existencia humana. Al principio, sólo interesó el conflicto en su relación con la neurosis. Se destacó su potencia destructiva, por lo que se consideró como alteración del equilibrio interno y, por tanto, como alteración del desarrollo normal... Contrapuestos a esto (...) puede ser visto como aquella concepción que acentúa el poder constructivo del conflicto (Krauss, 1933). El conflicto es, por esencia, en el ser humano normal, un estado de tensión constructivo (185). No obstante es importante destacar el rol que juega cada persona en cómo reconstruye sus redes con el fin de evitar el conflicto. 


\section{El adulto mayor en la normativa argentina}

En lo que refiere al derecho de las personas de edad, el Código Civil y Comercial vigente desde agosto de 2015 para nuestro país lo trata dentro del Título I Libro Primero «Persona Humana». Se encuentran otras figuras implícitamente vinculadas con los adultos mayores en el Capítulo 3, referido a los derechos y actos personalísimos, entendidos como aquellos derechos y actos que son inherentes a la persona en su calidad de tal sin ningún tipo de distinciones (Marzioni, 2016:86). Esto está refrendado por todos los tratados, congresos, declaraciones internacionales desde la Asamblea General del Envejecimiento Viena 1982. Por primera vez en la legislación argentina se trata al adulto mayor como una persona humana, en donde este grupo como tantos otros fueron insertos desde una metodología diferente a la tradición histórica, basado en principios y reglas, principalmente para el ejercicio de los derechos; teniendo en cuenta que están destinadas a todos los ciudadanos. Estos criterios fueron los que se consignaron aportando pautas para la interpretación e integración al aplicar la ley. Se destaca la importancia de esta última como fuente sin desechar el resto. Se aboga por una interpretación amplia conforme a la Constitución Nacional y los tratados internacionales donde nuestro país es parte; haciendo especial hincapié en la necesidad de que el juez recurra siempre a la interpretación y/o integración; evitando en lo posible como última ratio la declaración de inconstitucionalidad. Ello es jurisprudencia reiterada de la CSJN (Fallos: 228:325; 290:83; 393:290; 301:962; 324:3345, 4404; 335:645). ${ }^{3}$

De allí la importancia de que los profesionales encargados de redactar normativas y hacer jurisprudencia le den espacio a las diversas investigaciones centradas en la diversidad de experiencias de vida, según el contexto socio-político-económico-cultural en el que están inmersos los sujetos; las representaciones sociales sobre el envejecimiento y su impacto en la biografía subjetiva de cada persona mayor, para así tener en la actualidad un derecho práctico que refiera a ellos como "persona humana» con sus particularidades sociales, culturales y subjetivas. Y así dar cuenta del necesario y exitoso vínculo entre investigaciones en ciencias jurídico-sociales en áreas de interés en el avance en materia de derechos ciudadanos efectivos.

3 Código Civil y Comercial de la Nación. Proyecto del Poder Ejecutivo de la Nación redactado por la Comisión de Reformas designada por decreto 191/2011. Lorenzetti, Ricardo Luis (presidente); Highton de Nolasco, Elena, Kemelmajer de Carlucci, Aída. Presentación del Proyecto por Ricardo Luis Lorenzetti. Rubinzal-Culzoni Editores, Santa Fe, 2012, ps.510 y ss. 


\section{La imagen social y la lesión de derecho}

La imagen social del envejecimiento de no ser desandada contribuye al aprovechamiento en determinados momentos de las personas de edad; constituyendo lo que el derecho trata en el Título IV Libro Primero CCC. Refiere a los hechos y actos jurídicos y los vicios de los mismos. En especial la lesión de derecho. El Código establece la posibilidad de demandar la nulidad o la modificación de los actos jurídicos cuando una de las partes obtiene una ventaja patrimonial evidentemente desproporcionada y sin justificación, explotando la necesidad, debilidad síquica o inexperiencia de la otra (art. 332).

Se considera que - por su salud física y/o psíquica-, muchos adultos mayores pueden quedar comprendidos en el grupo protegido por esta figura, específicamente atendiendo a la debilidad psíquica, vinculada con el estado patológico de la persona, que le impide tener una dimensión plena de las consecuencias del acto que realiza, provocando una situación de inferioridad captada y aprovechada por la otra parte (Caramelo et ál., 2015:539).

\section{Las personas mayores incorporan el estigma}

Las representaciones sociales sobre los modos de ser y actuar de acuerdo a una etapa de la vida se interiorizan en el sujeto a través del procesamiento subjetivo que realiza cada persona de las expectativas sociales sobre su accionar, las cuales se encuentran vinculadas a lo esperable para una cierta edad, entre otras cuestiones. La identidad de cada sujeto es construida a partir de un proceso en el cual cada sujeto se autodefine en interrelación simbólica con otros individuos. Es decir que los lazos sociales construidos, están mediados por objetos simbolizados de diferente manera según los diferentes contextos socio-históricos-culturales. Por ejemplo las categorizaciones sobre qué es ser viejo actualmente, dista mucho de la forma de verlo en la Edad Media.

El sujeto interioriza las expectativas que los otros miembros de la sociedad esperan de su accionar. La identidad constituye la cultura internalizada - roles, actitudes, formas de vestir, hablar, caminar- en contraste y asimilación con otras personas. El proceso de identificación permite pensar en identidades dinámicas, heterogéneas, cambiantes y difusas, según los contextos socio-histórico específicos a través de los cuales cada sujeto toma repertorios culturales para diferenciarse respecto a otro. En ese proceso se establece su yo identitario a través de la asignación identificatoria 
cultural en relación con atributos estandarizados. El sujeto conceptualiza a los otros y construye el autoconcepto afirmante de su propia identidad.

La pérdida sucesiva del autocontrol emocional, corporal y contextual contribuye al incremento de los conceptos estigmatizantes sobre su identidad, adoptados por las propias personas mayores, al decir por ejemplo, que ya no quieren molestar a la familia, no pretenden ser un estorbo. La construcción valorativa -positiva o negativa- que las personas mayores tengan sobre su propio concepto depende de la visión de su cuerpo, su identidad y las capacidades y habilidades que suponen poseer, lo cual está en íntima relación con las percepciones sobre sí mismo que reciba de los otros significativos: familiares, amigos, sociedad e institución.

\section{La capacidad y autonomía de las personas de edad}

La capacidad de la persona humana está contemplada en los artículos 22 y 23 del Libro Primero Parte General Título I del CCC. La norma establece que toda persona humana goza de la aptitud para ser titular de derechos y deberes jurídicos; pudiendo limitarse o privarse legalmente esta capacidad respecto de hechos o actos jurídicos determinados. En cuanto a su ejercicio dispone que la persona puede ejercer sus derechos por sí misma, excepto las limitaciones expresamente previstas en el Código y en una sentencia judicial.

La capacidad general de ejercicio es la regla y se presume, «aun cuando - el adulto mayor en este caso- se encuentre internado en un establecimiento asistencial» (art. 31). Las limitaciones a la misma son de carácter excepcional y obligatoriamente deben ser decretadas por juez competente. Ante la necesidad de restringir dicho ejercicio se aplicarán los llamados «sistemas de apoyo al ejercicio de la capacidad». Consisten en medidas de carácter judicial o extrajudicial que facilitan la toma de decisiones para dirigir su persona, administrar sus bienes y celebrar actos jurídicos en general, con la finalidad de promover la autonomía, facilitar la comunicación, comprensión y manifestación de su voluntad para el ejercicio de sus derechos. En consecuencia, la declaración de incapacidad y la designación de un curador son medidas de carácter extraordinario.

El codificador ha puesto de relieve en el caso el «principio de la autonomía de la persona». Este principio es definido por Nino como la situación en... - que siendo valiosa la libre elección individual de planes de vida y la adopción de ideales de excelencia humana- el Estado (y los demás individuos), no debe interferir con esa elección o adopción, limitándose a diseñar instituciones que faciliten la persecución individual de esos planes de vida 
y la satisfacción de los ideales de virtud que cada uno sustente e impidiendo la interferencia mutua en el curso de tal persecución. (Nino, 1984:135).

Este principio guarda relación con los de «independencia» y de «participación», consagrados en los Principios de ONU para personas de edad 1991.

Un novedoso supuesto contemplado por la nueva normativa, refiere a la internación sin consentimiento de la persona (art. 41) -tenga o no restringida su capacidad-. La sentencia que la pronuncia requiere estar fundada en el dictamen de un equipo interdisciplinario; no obstante que conforme art. 37 in fine el mismo para expedirse conserva la sola facultad de decisión previa consulta de opinión de otras ciencias especializadas. Esta medida procede solamente ante existencia de riesgo cierto e inminente, de un daño de entidad para la persona protegida o para terceros; recurso terapéutico de carácter restrictivo y por el tiempo más breve posible.

La referencia sobre el derecho a la capacidad y autonomía de la persona mayor con las especificaciones de párrafos anteriores adquiere una relevancia destacable, ya que contribuye no sólo a la defensa un derecho ciudadano; sino a frenar la reproducción de estereotipos sociales que consideran a las personas mayores como despojadas de un sinnúmero de capacidades y forma de actuar autónomas. Ello va acompañado de prácticas familiares, institucionales y sociales, tendientes a realizar actividades en nombre de ellas, suponer que son sujetos que ya no pueden realizar ciertas destrezas, etc. Y pone de relieve que los jueces al sentenciar han tenido en cuenta estas características del envejecimiento activo (autonomía y capacidad), dando lugar a la efectivización de las mismas, aun cuando el sujeto se encuentre - por distintas particularidades de su vida - viviendo en una institución de cuidados.

\section{Derecho sobre el propio cuerpo y a la sexualidad}

Este apartado pone de relevancia cómo la normativa, al mentar los derechos sobre el propio cuerpo y la propia vida, refiere a la importancia de las representaciones sociales sobre la sexualidad en la vejez. Es un hecho valorable es que la jurisprudencia contribuya a desarmar los estereotipos negativos sobre el envejecimiento, disociando a las personas mayores como sujetos asexuados.

Este punto guarda relación con el Cap. 4 Título Preliminar CCC en lo que hace a la titularidad de derechos sobre sus bienes (art. 15) y derechos sobre el cuerpo humano o sus partes (art. 17). Uno refiere a la titularidad material sobre bienes; el otro al cuerpo humano, siempre respetando los valores allí descriptos. 
Dentro del derecho al propio cuerpo existen tres instrumentos jurídicos que han sido receptados por el código vigente: a) Consentimiento informado para actos médicos e investigaciones en salud (art. 59). Es una decisión especial de confianza expresada como declaración de voluntad expresa del paciente, emitida luego de recibir información clara, precisa y adecuada respecto a su estado de salud, el procedimiento propuesto, los beneficios esperados, los riesgos, molestias y efectos adversos previsibles, etc. Incluye: el derecho a rechazar procedimientos quirúrgicos, de hidratación, alimentación, de reanimación artificial o al retiro de medidas de soporte vital, cuando sean extraordinarios o desproporcionados en relación a las perspectivas de mejoría, o produzcan sufrimiento desmesurado, o tengan por único efecto la prolongación en el tiempo de ese estadio terminal irreversible e incurable. La doctrina del consentimiento informado se aplica cuando existan situaciones de urgencia que justifiquen que el facultativo dé preeminencia al valor vida por sobre a la libertad. b) Directivas médicas anticipadas: constituye una forma moderna de anticipar una problemática que aqueja a muchos adultos que estando o no cerca de su fin material, se encuentran preocupados para el caso de no poder decidir autónomamente o por estar en situación de fragilidad y/o vulnerabilidad.

El Código de Vélez no contaba con normas para estas directivas. Encuentran sustento en el art. $19 \mathrm{CN}$; en elaboraciones de doctrina y jurisprudencia; art. 11 Ley 26529 modificada por Ley 26742.

El derecho a la dignidad de la vida debe insertarse en una perspectiva que incluya la dignidad del proceso del morir, sin que implique recurrir a la eutanasia (Art. 6o CCC). La persona plenamente capaz puede anticipar directivas y conferir mandato respecto de su salud y en previsión de su propia incapacidad; designando a las personas incluso que podrán expresar el consentimiento para los actos médicos y para ejercer su curatela, quedando exceptuadas las directivas que impliquen desarrollar prácticas eutanásicas, las que se tendrán por no escritas. Si bien el articulado no establece una forma determinada, el citado 11 dispone que deben formalizarse por escrito ante escribano público o juzgados de primera instancia con la presencia de dos testigos. Son denominadas actos de autoprotección, registradas en muchas provincias en procura de facilitar la prueba de autenticidad del documento y garantizar, con su inscripción, el conocimiento de los sujetos a intervenir (Cfr.: Ley 14154 Provincia Buenos Aires; Ley 6212 de Chaco; Ley 4263 de Río Negro; Ley 2611 de Neuquén).

En el derecho comparado se lo llama testamento de vida o testamento vital. Está relacionado con la autonomía de la voluntad, el consentimiento 
informado y el derecho a la información. Su origen se remonta a 1967 en EE.UU. Diez años después en el Estado de California se promulga una ley que lo permite. Más tarde es incluido en el Código Civil de Canadá con el nombre expreso «testamento de vida». Debido a la naturaleza de la institución en España le llaman voluntades anticipadas. c) Exequias: La persona plenamente capaz puede disponer por cualquier forma, el modo y circunstancias de sus exequias e inhumación, así como la dación de todo o parte del cadáver con fines terapéuticos, científicos, pedagógicos o de índole similar (arts. 17 y 61) (Marzioni:87).

La doctrina jurídica al establecer este tipo de cuestiones, nos ayuda a reflexionar sobre las situaciones referidas a la corporalidad envejecida. El cuerpo viejo es disfuncional a la representación social que se construye alrededor de la belleza, la sexualidad y el deseo. En torno a las personas mayores aparece una variable de estigmatización: la piel, y esa variable se constituye, según Salvarezza (2013) como la vara para medir lo deseable o no de un determinado cuerpo. Quiere decir, el sujeto para ser objeto de deseo debe presentar un tipo de piel suave, sin arrugas o marcas y con fortaleza. Conlleva a falta de contacto, nos muestra la propia próxima vejez e implica sentimientos de soledad y desasosiego en las personas mayores, pérdida de autonomía/autoestima, deviene en mayor dependencia, proclividad a tener enfermedades asociadas a la vejez, discriminación, auto estigmatización y aislamiento.

El primer paso para preservar la propia sexualidad, que para mucha gente es sinónimo casi de preservar la propia personalidad, es tomar conciencia de que la sexualidad, si se cultiva, puede perdurar, y normalmente perdura, durante toda la vida en ambos sexos; teniendo en cuenta incluso el repertorio de prácticas eróticas que hacen al vínculo afectivo (Confort, 1997:241). Es el disfrute con todo lo que el otro es. Sexo es una cosa; sexualidad es el sinnúmero de detalles que hacen al diario vivir: el entorno de amor; caricias, el compartir, dialogar, aromas, el olor de la piel, su textura. El enfoque hedonista propone superar la concepción dual del ser humano y se busca trasmitir y lograr una visión más integrada, completa de la persona, en la cual la sexualidad se concibe como una realidad compleja que abarca la vida entera (Melendo, 1991).

La construcción de lo deseable es una construcción social en donde el cuerpo viejo no está incluido, ya que está pensado a través de la lógica patológica que lo identifica con enfermedad, senilidad, fragilidad, que necesita de ayuda constante, crecientemente dependiente de su entorno y de profesionales capacitados en enfermedades asociadas a la vejez. 
Redes sociales, rol de las personas de edad y relaciones de familia

Las redes sociales son entidades relacionales complejas de tipo colectivo que tienen atributos morfológicos e interactivos que les son propios y como fin la satisfacción de las necesidades materiales, afectivas y de información de cada uno de sus miembros. Los morfológicos refieren a la amplitud (número de miembros que integran la red), a densidad (cantidad de vinculaciones que los miembros establecen entre sí).Los interactivos están relacionados con la idoneidad, intensidad y duración de los vínculos. Por las necesidades a satisfacer y formas de intercambio se dividen en primarias o informales y secundarias o formales (Castellanos y Tauquer, 1998).Cada persona nace en el interior de una red, pero en el curso de su vida hace elecciones que van modificando las estructuras y la funcionalidad de la misma. En su interior se construyen alianzas, conflictos, situaciones positivas o negativas, y en determinados momentos de la historia del hombre configuran un ámbito de sostén y pueden constituirse en elementos de solidaridad de importante relevancia colectiva.

En la intervención psicosocial van unidas al apoyo social. ${ }^{4}$ Específicamente mencionado en El Plan de Acción Internacional para la Ancianidad redactado como parte de la Asamblea Mundial de Naciones Unidas sobre el Envejecimiento Viena 1982. Este aprueba dentro del módulo «Bienestar» «se reconoce como principio básico el que los ancianos deben disfrutar en sus familias y comunidades de una vida plena, saludable, segura y satisfactoria e integrada, potenciando el apoyo familiar y el voluntariado, promoviendo programas que prevengan su aislamiento social y faciliten su integración». ${ }^{5}$ Las redes sociales y el apoyo social son importantes fuentes de recursos para satisfacción de necesidades y la conservación del sentido de utilidad social; potenciando la autoestima del adulto mayor, su imagen, concepto y respeto de la población hacia ellos.

El CCC en el Libro Segundo trata las Relaciones de Familia, institución fuertemente influenciada por la «constitucionalización» del derecho civil ante la incorporación de los tratados de derechos humanos con jerarquía constitucional (art. 75 inc. 22 CN). El Anteproyecto del Código explicita que

4 Apoyo social: todo proceso de transacciones interpersonales, de recursos emocionales, instrumentales e informativos de ayuda ya existentes en la comunidad — redes sociales - que se dan entre los miembros de una comunidad (Goettlieb, 1981), dirigidos fundamentalmente a proveer bienestar (Schumaker y Brownell, 1984).

5 Asamblea General de las Naciones Unidas, Resoluciones 46/91, 46/94, 45/106(1992). Objetivos Mundiales para el año 2001. "El Plan de Acción Internacional sobre el Envejecimiento". Viena, Austria. 
existe una democratización de la familia. Al tratar «derecho de familias» en plural: comprende todas las uniones posibles; basada en el Art. 14 bis de nuestra carta magna al abarcar la llamada protección integral de la familia que comprende también:

- Atribución de la vivienda. El Art. 443 CCC establece la posibilidad de que uno de los cónyuges pida la atribución de la vivienda familiar, sea el inmueble propio de cualquiera de ellos o ganancial, atendiendo a la edad de los mismos y a los intereses de otras personas que integran el grupo familiar; pudiendo incluirse aquí a adultos mayores que convivían con el matrimonio. Este es un derecho de uso que no altera la propiedad del inmueble.

- Derecho de comunicación. Este derecho era conocido como derecho de visitas. El art. 555 en Parentesco refiere a aquellas personas que tienen a su cargo el cuidado de personas con capacidad restringida, enfermas o imposibilitadas. Contempla que se debe permitir la comunicación de éstos con sus ascendientes, descendientes, hermanos bilaterales o unilaterales y parientes por afinidad en primer grado, $u$ otras personas que justifiquen un interés afectivo legítimo. El derecho de comunicación se puede conceptualizar como «... un derecho/deber que consiste en la vinculación periódica y de manera asidua entre dos personas unidas por un determinado grado de parentesco» (CC art. 646).

- El adulto mayor en su rol de abuelo. El Código establece expresamente algunas prerrogativas dirigidas a regular el vínculo entre abuelos y nietos. Bajo el título Responsabilidad Parental entre los deberes y derechos de los progenitores, se incluye en el inciso e) del Art. 646...respetar y facilitar el derecho del hijo a mantener relaciones personales con abuelos... El art. 668 determina la obligación alimentaria a los ascendientes: el reclamo puede realizarse en el mismo proceso en que se demanda a los progenitores o en proceso diverso, acreditando verosímilmente las dificultades del actor para percibir los alimentos del progenitor obligado.

- Deberes de los hijos. El artículo 671 enumera tres deberes: respetar a sus progenitores; cumplir con las decisiones de los progenitores que no sean contrarias a su interés superior; y prestar a los progenitores colaboración propia de su edad y desarrollo y cuidar de ellos u otros ascendientes en todas las circunstancias de la vida en que su ayuda sea necesaria. Este último deber puede tener especial trascendencia respecto de los adultos mayores, en su rol de progenitores u otros ascendientes necesitados de cuidado, frente a determinadas situaciones de vulnerabilidad, debido a problemas de salud, insuficiencia de medios económicos, etcétera. 
El Art. 537 deberes y derechos de los parientes enumera quienes se deben alimentos entre sí; estableciendo la obligación alimentaria de los descendientes hacia los ascendientes: obligados preferentemente los más próximos en grado y los que estén en mejores condiciones para proporcionarlos.

Todos estos nuevos institutos específicamente reglados ponen de manifiesto cómo el derecho se ha ido acomodando a la forma de pensamiento social y a través del sentido común está modificando la manera en que la sociedad construye a una representación social de la vejez más positiva y comprensiva de un nuevo paradigma de derechos y libertades para estas personas.

\section{Los Principios Generales y de los procesos de familia}

Regresando al inicio del artículo estas «representaciones sociales de la vejez» y las imágenes de este grupo al generar transformaciones jurídicas y sociales inéditas para nuestro país, juegan un papel importante cuando se tratan los institutos jurídicos en el CCC vigente. En especial cuando el codificador da relevancia al paradigma de la la «constitucionalización» del derecho; e involucra principios rectores materiales y procesales, prácticas, valores jurídicos y sociales.

El Código recepta junto al ejercicio de derechos el de buena fe; abuso y lesión de derecho; derechos individuales y de incidencia colectiva (Arts. 9,10 y 14 ) aplicables también a la PAM. Orienta al resto del articulado y son ampliamente receptados por la jurisprudencia. Trata los principios del derecho de familia: tutela judicial efectiva, inmediación, buena fe y lealtad procesal, oficiosidad, oralidad y acceso limitado al expediente. Regula el acceso a la justicia de personas vulnerables (707): personas mayores con capacidad restringida derecho a ser oídas en todos los procesos que les afecten directamente. Las 100 Reglas de Brasilia sobre el Acceso de Justicia de las personas en condiciones de vulnerabilidad dice: «...repensar su condición de sujeto de derecho a fin de situarle ante la ley realmente en igual posición que los demás así como la necesidad de fortalecer el reconocimiento de sus derechos como verdaderos derechos subjetivos» (Davobe, 2002). Están presentes en los principios de Naciones Unidas a favor de las personas de edad adoptados por la Asamblea General 16/12/91, junto con los de: independencia, cuidados, autorrealización y dignidad. El de "participación» es uno de los consagrados internacionalmente receptados en la normativa argentina junto a: acceso a la justicia y resolución pacífica de los conflictos. 


\section{La contribución de la ciencia para cambiar el paradigma sobre el envejecimiento}

Todos los argumentos supra expresados desembocan en hacer posible una forma de representación social que es imprescindible que sufra modificaciones en la subjetividad de los integrantes de nuestra sociedad, en la objetividad con que la justicia, los medios de comunicación social y las normas tratan al adulto en que se van a convertir tarde o temprano. Esto nos lleva inexorablemente a hablar de un nuevo paradigma sobre la vejez que el grupo de investigación ha dado en llamar un "modelo de ciudadanía».

La concepción del paradigma implica la reflexión en torno a los sujetos implicados en un desarrollo multidimensional: biológico, psicológico, cultural y social. Es construido y elaborado por el sujeto en los múltiples ámbitos de su vida (familia, trabajo, amigos, etc.) durante toda su existencia. En otro lenguaje preguntarse cómo la ciencia contribuye a cambiar el estereotipo que la sociedad ha ido formando respecto al tema del envejecimiento y su propia vejez individual. Para comprender la forma en que las personas mayores viven su propia vejez es importante tener en cuenta el tipo de acontecimientos históricos que cada sujeto vive, el momento específico en el que los vive, la interdependencia de la red de relaciones sociales que son compartidas, y la agencia que el propio sujeto puede realizar entre un cúmulo de expectativas y posibilidades.

Vale traer a colación el Art. 2 CCC de nuestro país: la constitucionalización del derecho privado, los principios generales y del proceso de familia, los valores y las prácticas sociales que conllevan a un modelo de ampliación de ciudadanía que lentamente se conforma en esta sociedad en que vivimos.

\section{Conclusión}

Tanto el tema normativo como sociológico referido busca la igualdad real de oportunidades consagrada en el inc. 23 del Art. 75 CN. Los aspectos valorativos son tratados en los Fundamentos del Anteproyecto de Código. Destaca para personas de edad un código de igualdad. Una igualdad real basada en normas orientadas a plasmar una ética de los vulnerables, basada en el principio de no discriminación. Este ejercicio de derechos del Título Preliminar habla de que los destinatarios son ciudadanos entre ellos las personas de edad. Esta ciudadanía supone clausurar la fisura de la discriminación inversa; concuerda con el código de igualdad y con el inc. 23 Art. 75 
CN; cuando habla de "promover medidas de acción positiva que garanticen la igualdad real de oportunidades y de trato,...el pleno goce y ejercicio de los derechos reconocidos por esta Constitución y por los tratados internacionales vigentes sobre los derechos humanos, en particular... ancianos y las personas con discapacidad».

Se acerca con estas innovaciones legislativas y con el bloque de constitucionalidad a receptar posiciones reclamadas hace tiempo por la gerontología para su debida protección. Proclamada en la última declaración de Costa Rica 2017 receptada por Ley para Argentina, regulando derechos y libertades de las personas mayores como un ciudadano más entre sujetos amparados.

Esta "constitucionalización» abre un nuevo paradigma normativo sobre el espíritu de humanización; revalorización de derechos humanos y centralidad de la persona. Resignifica un nuevo modelo de ampliación de ciudadanía facilitador de la protección integral y efectiva de los derechos y libertades para la PAM.

La doble perspectiva puesta en juego en este trabajo tiende dar cuenta de los constantes procesos oscilantes que ocurren en la vida de todo sujeto, donde los cambios sociales, históricos, culturales, familiares y jurídicos tienen injerencia en las biografías de los sujetos. Y abre un camino insospechado para las Ciencias Jurídicas y Sociales al otorgar criterios de proporcionalidad, racionabilidad, eficiencia, seguridad jurídica en la interpretación y argumentación para las personas de edad.

\section{Entrevistas}

BIRGIN, H. Y COHEN, B. (2006).Acceso a la justicia como garantía de igualdad. Instituciones, actores y experiencias comparadas. $1^{\text {a }}$ edic. Buenos Aires: Biblos.

CARAMELO, G.; PICASSO, S. Y HERRERA, M. (2015). Código Civil y Comercial de la Nación comentado. Infojus. Ciudad Autónoma Buenos Aires, Disponible en: http://www.infojus.gob.ar/ docs-f/codigocomentado/CCyC_Comentado_Tomo_I\%20(arts.\%201\%20a\%20 400).pdf
CASTELLANOS, B. Y TAUQUER, N. (1998). Redes sociales. Anuario de la Revista de la Universidad Nacional de Mar del Plata. CÓDIGO CIVIL Y COMERCIAL DE LA NACIÓN (Introducción y revisión general: Alberto J. Bueres). Buenos Aires: José Luis Depalma editor, Hammurabi.

CONFORT, A. (1997). Una buena edad: la tercera edad (trad.: Ignacio Ruiz Alcaín). Madrid: Debate.

DAVOBE, M.I. (2002).Los derechos de los ancianos. Madrid: Ciudad Argentina. 
FERRAJOLI, L. (2017) “Cittadinanza. Italia: Edit. Trotta.

GASTRÓN, L. (2001). La vejez como objeto de las representaciones sociales. En Jornadas Gino. Buenos Aires: IIFCS, Instituto de Investigaciones Gino Germani. Disponible en: http://bibliotecavirtual. clacso.org.ar/ar/libros/argentina/germani/gastron.rtf

(Comp.) (2013). Dimensiones de la representación social de la vejez. $1^{\mathrm{a}}$ edic. Mar del Plata: EUDEM.

IACUB, R. (2014). Identidad y envejecimiento. Buenos Aires: Paidos.

JODELET, D. (2008). El movimiento de retorno al sujeto y el enfoque de las representaciones sociales. Cultura y representaciones sociales. Educación básica e inclusión: un estudio de representaciones sociales. Disponible en: http://www.culturayrs.org. $\mathrm{mx} /$ revista/ num5/jODELEt.html

LEHR, Ú. (1980) Las situaciones problemáticas ¿poseen poder destructivo o constructivo? En: Psicología de la senectud (trad. al castellano de Alfredo Guera Miralles). Barcelona, España: Herder citado por Marzioni, Cristina (2011) en CD.ROM Interactivo, Gerontología jurídica y social. - 1a ed. - Santa Fe: Univ. Nacional del Litoral.
LLORENTE CRABERO, M. (1991). Vejez y soledad: mito o realidad. INSERSO $\mathrm{N}^{\circ} 74$ : Minusválidos. Madrid, España: Ministerio de Asuntos Sociales.

MARZIONI, C. (2019). Edad avanzada y demografía. En El acceso a la justicia para los adultos mayores. Un modelo de ampliación de ciudadanía, Santa Fe, Edic. UNL, a edición.

(2016). "Transformaciones jurídicas y sociales en el nuevo Código Civil y Comercial de la Nación Argentina para los adultos mayores" en Revista Nueva Época $\mathrm{N}^{\circ} 10$, Santa Fe: Ediciones UNL.

MELENDO, M. (1991). Educación afectivosexual integradora. $3^{a}$ edad. Madrid, España: Villena.

NINO, C.S. (1984).Ética y Derechos Humanos. Un ensayo de fundamentación. Buenos Aires: Paidós.

RESOLUCIONES 46/91, 46/94, 45/106 (1992) de la Asamblea General de las Naciones Unidas, Objetivos Mundiales para el año 2001. El Plan de Acción Internacional sobre el Envejecimiento. Viena, Austria.

SALVAREZZA, L. (2013).La vejez. Una mirada gerontológica actual. Buenos Aires: Paidós. 


\section{Cristina Ester Marzioni} Abogada FCJS-UNL; especialista Derecho Familia/Menores, docente: Teoría del Derecho, Filosofía del Derecho, Seminario Gerontología Jurídica y Social en grado (LTS) y pregrado en Tecnicatura Previsión Social (FCJS); investigadora-Directora proyectos y programas de actividades científicas y tecnológicas: CAI+D "A" “Un modelo de ampliación de ciudadanía a partir de las Transformaciones jurídicas y sociales del CCyC de la Nación Argentina para los adultos mayores desde la ciudad de Santa Fe, y PACT No 28-2017/20 FCJSUNL. Gerontóloga Univ. Itinerante Internacional Grenoble-Francia-Europa convenio con Municipio Rosario, Sta Fe, Argentina. Ejercicio abogacía-1976/2019. Libros y artículos en revistas con referato externo e internacional (nacionales y extranjeras). Ponente/organizadora/asistente Congresos, Encuentros, Jornadas nacionales e internacionales. Categorizada II SPU16/6/2017- Comisión Región Centro Este N ${ }^{\circ} 1-5 / 5 / 16$.

\section{Lucía Viviana Billoud} Licenciada en Sociología FHC, UNL- Tutora Seminario Gerontología Jurídica y Social, LTS.FCJS; Cursa desde 2017 Doctorado Ciencias Sociales en FHC-UNL; investigadora grupo colaborador en proyectos $\mathrm{CAl}+\mathrm{Ds}$ “A", todos FCJS-UNL mencionados. Artículos en revistas nacionales con referato externo. Ponente/organizadora/asistente Congresos, Encuentros, Jornadas nacionales e internacionales.

\section{REGISTRO BIBLIOGRÁFICO}

Cristina Ester Marzioni y Lucía Viviana Billoud "LAS REPRESENTACIONES SOCIALES DE LA VEJEZ. UN MODELO DE AMPLIACIÓN DE CIUDADANÍA", en Papeles del Centro de Investigaciones, Facultad de Ciencias Jurídicas y Sociales, UNL, publicación semestral, año 9, número 20, Santa Fe, República Argentina, 2019, pp. 73-92. 